Stabb, to explore the chest by costo-chondral resection. About two inches of the second and third left rib-cartilages were resected and the patient, at the time I write, now reclines comfortably, and avers she can both breathe and swallow more easily, and does so.

One might legitimately, therefore, surmise a priori that when the central organ takes the initiative in congesting and encroaching upon the lungs, relief of intrathoracic pressure by costal resection might also in some cases be beneficial. This view, if you remember, was that which I put forward in a paper on "Pericarditis in Childhood" which I read before this society last year and which was later published in The LANCET.' It is, indeed, a view which I have advocated for several years, but without convincing others, possibly because I have not boldy put it into practice. The same timidity, however, has not been exhibited in Germany, where Braner, of whose work I was until recently unaware, has successfully treated several cases of adherent pericardium by causing surgeons to remove a sufficient amount of costo-chondral surface in the præeordia, and his example has been followed in Holland by Wenckebach in one case. I cannot now give the details of these cases, but it will suffice to relate (1) that the operation was not difficult, as one would expect; and (2) that the general effect in improving the action of the heart and in promoting an easier circulation was obtained by the procedure. All these cases were diagnosed as adherent pericardium, although the sac was not opened, and in some of them costo-pericardial anhesion under the surface removed was not found. The pericardial tethering was, therefore, assumed to be elsewhere, that is, pleuro-pericardial. This fact also; how. ever, has interest, for the question arises whetber mere cardiac bulk is not a disadvantage in these circumstances and whether, therefore, the justification does not arise for attempting to relieve pressure by the removal of a portion of the ribs and cartilages in the præcordia, in obedience to the indications given by the præcordial bulging of children, even when it may be assumed tbat actual pericardial tethering is absent. I think personally, we shall soon be justified in this matter in following John Hunter's advice to Jenner when the latter was too timid to vaccinate but thought be migbt do so with safety. "Why think?" said Hunter; "do it." I believe we shall also in this matter be able to "do it" with safety and with benefit, both to patients and to our own reputation.

\section{PANCREATITIS DUE TO DIRECT EXTEN- SION OF A MALIGNANT GROWTH OF THE GALL-BLADDER ALONG THE COMMON BILE AND PAN- CREATIC DUCTS.}

By A. W. MAYO ROBSON, D.Sc., F.R.C.S. ENG., HONORARY SURGEON TO THE DREADNOUGHT HOSPITAL; AND

\section{P. J. CAMMIDGE, M.B. LOND., D.P.H. CANTAB.}

THE following case appears to us to be of sufficient interest, both from a clinical and pathological point of view, to make it worthy of being reported.

The patient, a man, aged 61 years, was seen by one of us in consultation with Dr. Carter on the evening of March 2nd, 1907. He was extremely ill and it appeared clear to both his medical attendants and his friends that unless something could be done to relieve him he had not long to iive. He gave the history that he had been perfectly well up to 13 months previously, when he began to have some abdominal pain on the right side beneath the costal margin. Although be was able to go to business, he had to leave off work from time to time on account of more severe seizures of pain, the attacks resembling, and, in fact, being diagnosed as, gall-stone seizures. From the time of his first attack of pain he began to lose flesh and in November, 1906. after a more severe attack than usual, janndice supervened, but it cleared up in a fortnight. Three weeks before being seen he had had another severe attack followed by jaundice, which, however, had now subsided. With the jaundice the abdomen became swollen and very tender on the right side. For one week he had had some fever of an irregular type, associated with occasional shivering attacks and vomiting. At the time of the consultation he was markedly emaciated and very feeble, the abdomen was distended, but no fluid thrill could be felt. There was great tenderness on the right side of the abdomen, apparently due to local peritonitis, so that it was impossible accurately to palpate the region; nevertheless, gentle pressure revealed a distinct swelling which reached below the level of the umbilicus. It was hard, distinct, tender, and rounded and was apparently a distended gall-bladder. Above this swelling could be felt a hard nodule at the edge of the liver. 'The skin was deeply jaundiced, the urine was dark, and the fæces were pale. There was no odema of the legs and no evidence of ascites could be found. Immediately after the abdomen had been examined the patient had a shivering attack and the temperature went up at once to $104^{\circ} \mathrm{F}$. A diagnosis was made of suppuration in the gall-bladder, possibly associated with gall-stones and probably with malignant disease. An exploratory operation was recommended, and, although it was thought that the patient would be too ill to bear any extensive operative procedure, it was hoped that pus might be evacuated and so give relief.

Analyses of specimens of urine, fæces, and stomach contents were made on March 3rd with the following results.

Urine.-Reaction, acid; specific gravity, 1.020 ; albumin, nil; sugar, nil; acetone, nil; diacetic acid, nil; indican, nil ; bile, a well-marked reaction ; urobilin, nil ; urea, $2 \cdot 7$ per cent. ; chlorides, 0.4 per cent. ; phosphates, 03 per cent. ; microscopically, squamous and transitional epithelium "pancreatic" reaction (C), many fine crystals, soluble in 33 per cent. sulpharic acid in ten seconds (Fig. 1).

Faces -Appearance, soft, grey-brown, solid; reaction, alkaline; stercobilin, traces; microscopically, many fat globules, a few fatty acid and soap crystals, some undigested muscle fibre; organic matter, 91.5 per cent. of the dry weight; "total fat," 39.6 per cent.; "neutral fat," 31.8 per cent.; "combined fatty acid," 7.8 per cent. organic matter, not fat, 51.9 per cent.; inorganic ash, 8.5 per cent.

Stomach contents - Reaction to litmus, acid; congo-red reaction, deep blue; phloroglucin vanillin reaction, pink; lactic acid, traces; albumin, a well-marked reaction; albumoses and peptone, a well-marked reaction; mucus, a large amount ; dextrin, a well-marked reaction ; sugar, nil; blood, nil ; bile, nil ; microscopically, much glairy mucus, many fat globules, some starch granules, many sarcina, some yeast cells, a few bacilli. Quantitative examination: total acid, 0.12 per cent.; total chlorides, 0.32 per cent. inorganic chlorides, 0.22 per cent.; physiologically active hydrochloric acid, 0.10 per cent.

The conclusions drawn from the above results were stated as follows :-

The large amount of bile pigment in this specimen of urine shows that there is some serious obstruction to the free flow of bile into the intestine. The positive result of the "C-pancreatic" reaction point to there being active degenerative changes in the pancreas, probably of an inflammatory nature, and suggests that the cause of the cbstruetion to the bile flow is also interfering with the functions of the pancreas. The character of the pancreatic reaction, the presence races of stercobilin in the fæces, the normal proportion of physiologically active hydrochloric acid, and the presence of free hydrochloric acid in the vomit are against the obstruction being due to malignant disease of the head of the pancreas and suggest a diagnosis of impacted gall-stones in the common bile-duct. The excess of unabsorbed fat in the frces, together with the fact that this exces is entirely due to " neutral fat." tends to confirm the diagnosis of there being some interference with the functions of the pancreas. The excess of fat is, however, not so marked as is usually seen in malignant disease of the head of the gland and points to the defective digestion being due to an inflammatory lesion of the pancreas. The results of the analysis of the stomach contents are against a diganosis of primary malignant disease of the panereas or stomach, hut the microscopical characters and the presence of lactic acid suggest that there is probably some stagnation of the stomach contents.

The pathological analyses therefore pointed to there being a considerable degree of pancreatic inflammation associated with, and secondary to, obstruction of the common bile-duct and since the evidence available did not favour this being due to a malignant growth of the head of the pancreas it was inferred that it arose from the most common causenamely, an impacted biliary calculus in the pancreatic portion of the common bile-duct. The presence of free hydrochloric acid and the normal proportion of phyisologically active acid found in the stomach contents also tended, according to the investigation of Moore and his fellow-workers, to contraindicate a diagnosis of cancer elsewhere and favoured the opinion that the 
FIG. 1.

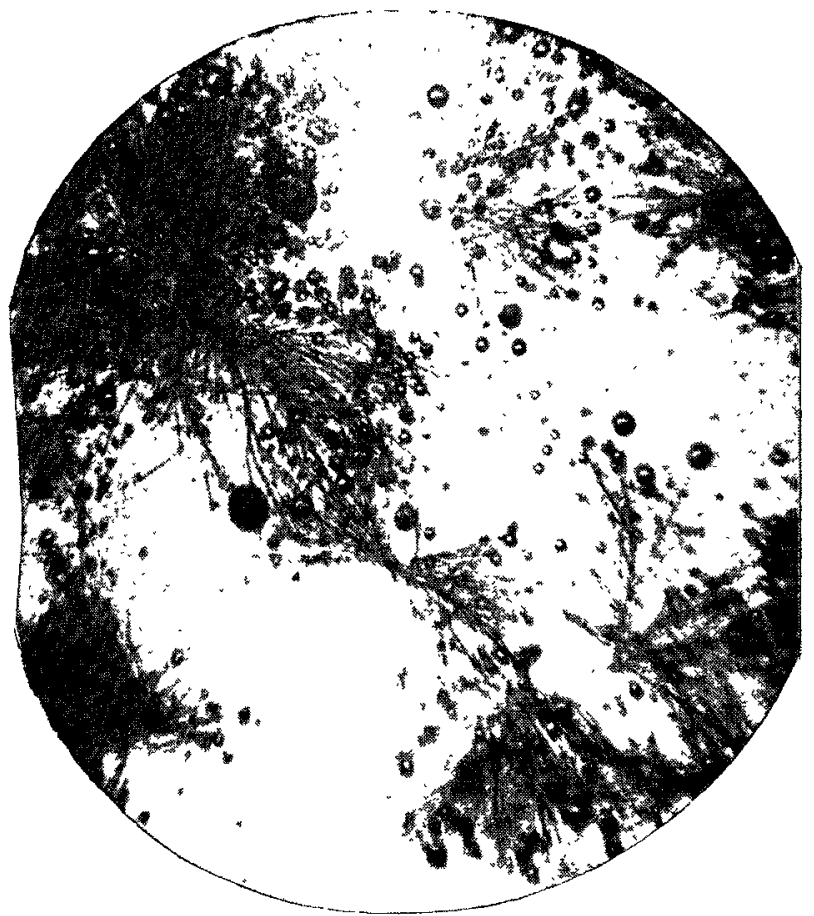

Crystals obtained from the urine bv the "c-pancreatic reaction." ( $\times 200$.

FIG. 3.

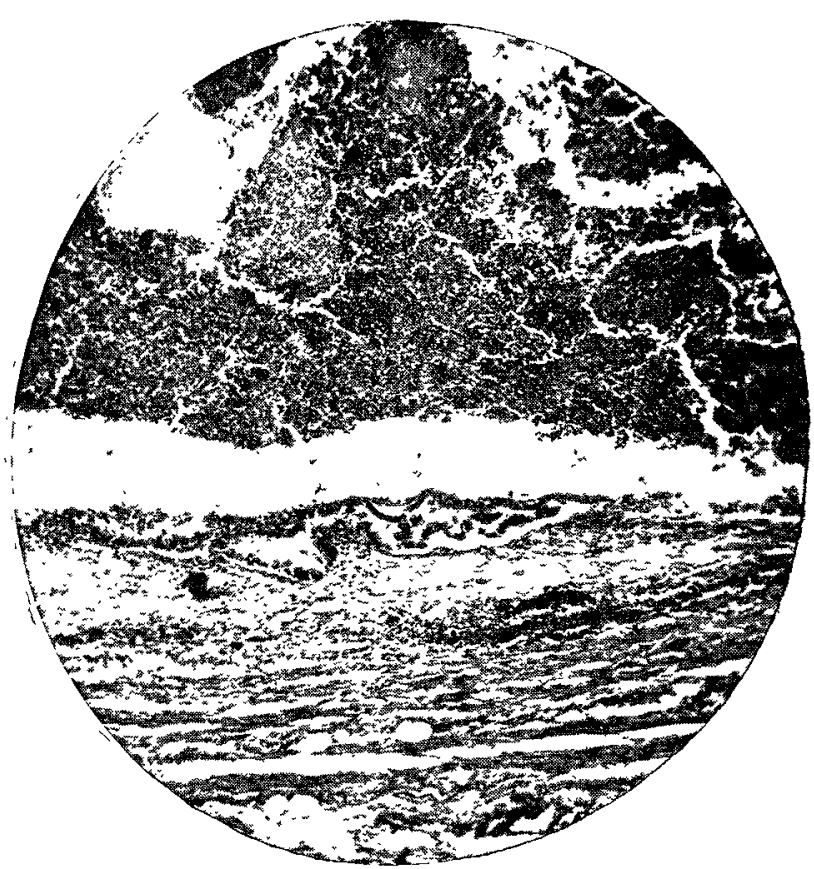

Section of the wall of the common bile-duct (below) and contents (above). $(\times 50$.

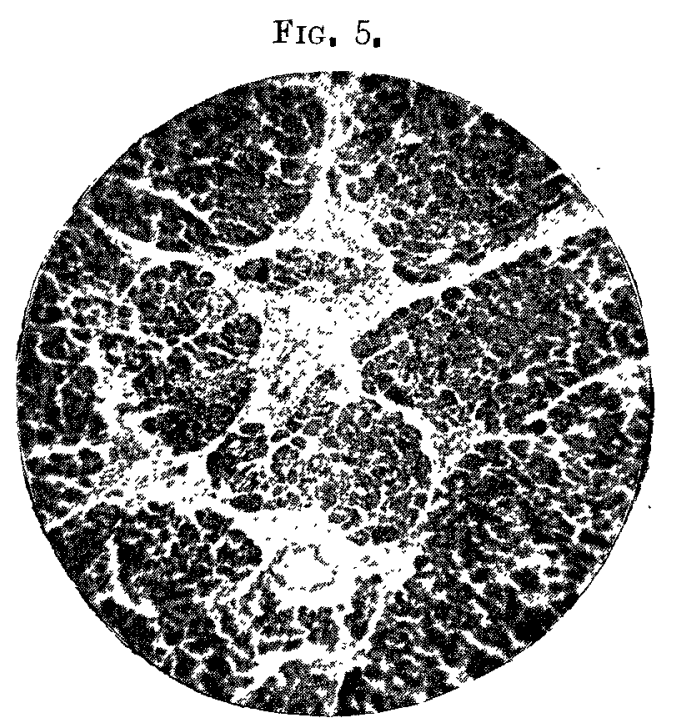

Section of the head of the pancreas midway between the duct of Wirsung and the periphery, showing interstitial pan-
creatitis and deposits of growtl. $(\times 50$.
Fig. 2.

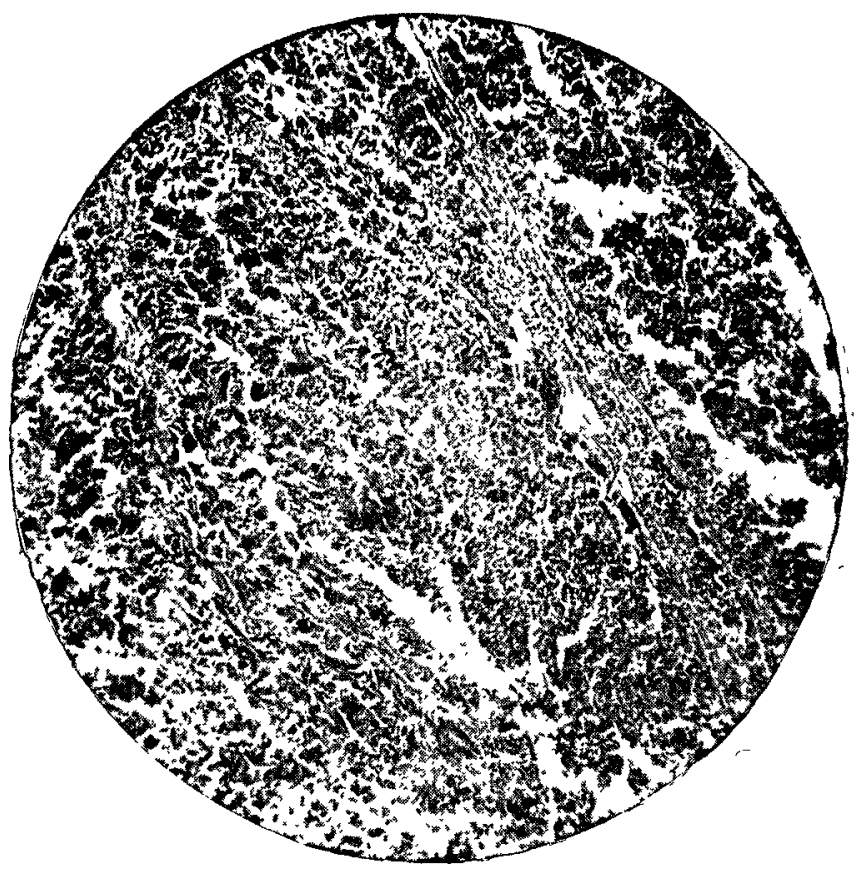

Section of the primary growth in the gall-bladder. $(\times 50$.

FIG. 4.

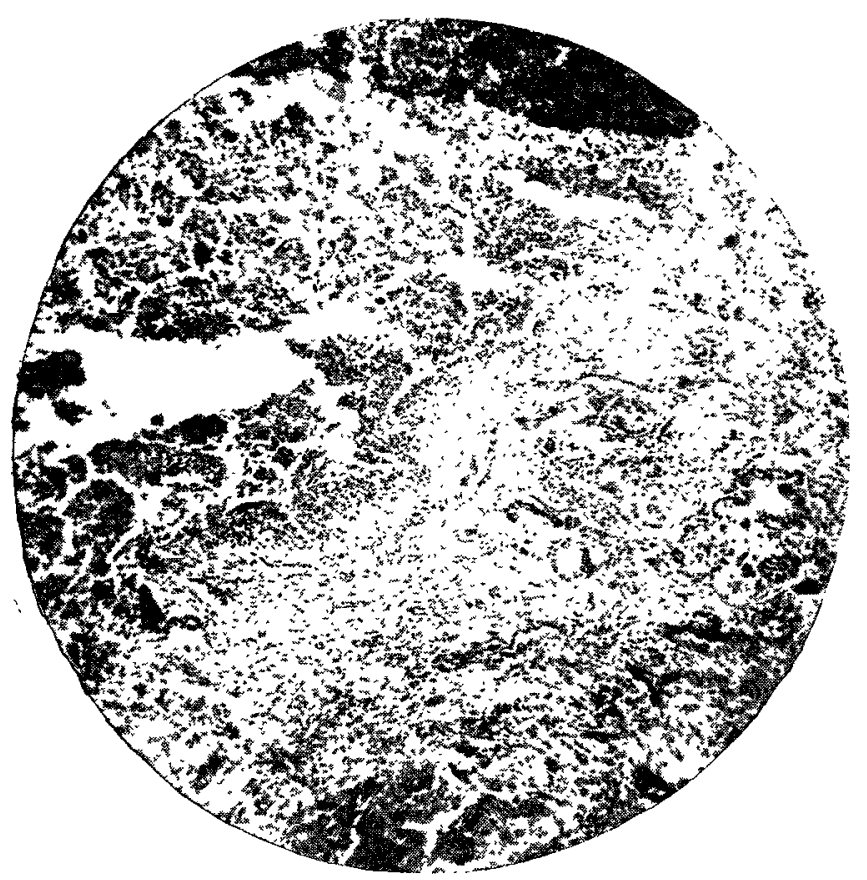

Section of the duct of Wirsung and adjoining tissue, showing the contents of the former and the penetration of the wall by the growth. $(\times 50$.)

Fig. 6.

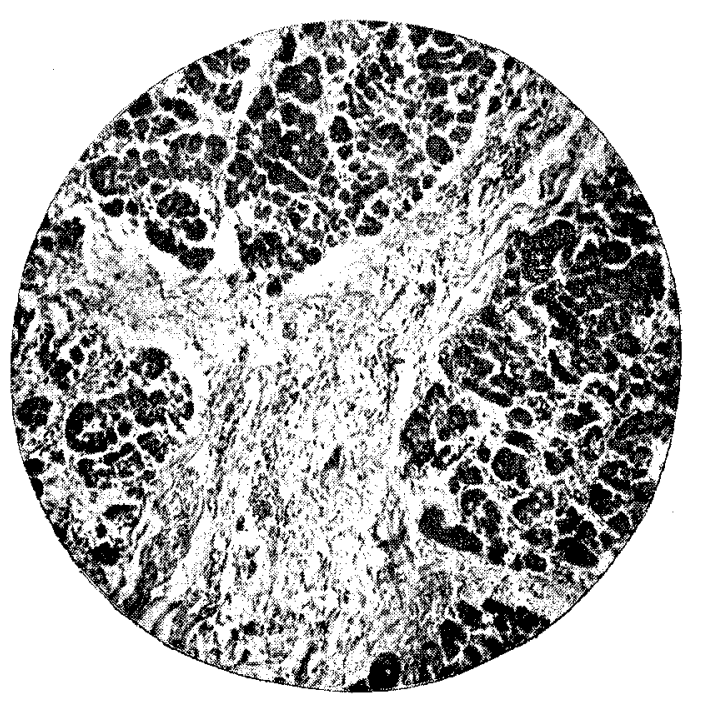

Section of the head of the pancreas near the periphery, showing advanced interstitial pancreatitis but no deposits of growth. $(\times 50$. $)$ 
obstruction was of a simple nature, but as in two other cases of growth blocking the common bile-duct high up we had found both free hydrochloric acid and a normal proportion of physiologically active acid in the material regained from the stomach after a test meal we did not lay much stress on this point. In both of these cases, however, we had failed to find any trace of stercobilin in the fæces, and there was not only a very large excess of "neutral fat" but the fæces also contained a high proportion of "combined fatty acid," so that the presence of stercobilin in this instance, together with the otber results of the chemical examination of the frees, inclined us to take the view that the obstruction was probably due to gall-stones. The only point not readily explained on this hypothesis was the evident stagnation of the stomach contents, but it was assumed that this was due to dilatation of the stomach from some independent cause.

The patient was removed to a nursing home, and on March 4th an exploratory operation was performed, a vertical incision being made over the centre of the tumour. Pus was soon reached and it was found that the abscess walls were composed of broken-down growth. A drainage-tube was inserted and the wound was closed as it was quite clear that nothing further could be done. The patient was temporarily relieved by the evacuation of the pus, but his pulse, which was very feeble before the operation, in a few hours became very rapid, and he only survived until the following day.

A partial post-mortem examination was made 18 hours after death, permission only being given for an examination to be made through the operation wound. The drainagetube was found to lead into an irregular cavity, lined with soft friable material, which occupied the position of the gallbladder, no trace of which could be found. The growth was intimately adberent to the pylorus, first part of the duodenum, and colon, so the stomach, duodenum, colon, liver, and pancreas were removed en masse for more detailed investigation. Dissection showed that the walls of the cavity varied from three-quarters of an inch to one inch in thickness, except anteriorly, where they consisted of a thin layer of inflummatory exudate. Above and behind it was bounded by the liver, while below it was adherent to the colon and pyloric extremity of the stomach. The line of demarcation between the liver substance and the growth was somewhat irregular but could be easily traced. No metastatic growths could be discovered in the liver. An examination of the interior of the stomach and intestine showed that the walls of the pyloric canal and the first two inches of the duodenum were adherent to, and invaded by, the growth. In several places fungating masses protruded into the lumen of the stomach and duodenum, but no penetration of the walls of the colon had taken place. The common bile-duct could be traced through the head of the pancreas and along the left margin of the growth to its upper extremity, where it was lost as a distinct canal, althongh the presence of bile-stained material indicated the direction in which it passed. The duct was found to be dilated and filled with soft, bile-stained material throughout its length. The head of the pancreas did not appear to be invaded by the growth and could be easily and cleanly separated from it. The pancreas, and especially the head of the gland, was larger and harder than normal. On section no evidence of any secondary deposits could be detected by the naked eye. On dissecting out the duct of Wirsung it was found to be dilated and to be filled with bile-stained débris, similar to that seen in the common bile-duct, for one and a half inches from its duodenal opening; beyond that it was filled with white opaque material free from any trace of bile.

Histological examination.-Preparations made from the walls of the cavity in the liver showed masses of columnar cells, arranged in more or less regular columns and alveoli separated by delicate strands of fibrous tissue (Fig. 2) Sections of the common bile-duct showed that its lumen was occupied by masses of columnar cells and amorphous débris. Many of the cells were deeply stained with bile. In some places continuous strands of five or six cells could be seen. The walls of the duct were thickened and infiltrated with patches of small round cells. In places irregular masses of columnar cells could be seen penetrating the walls (Fig. 3'. Sections of the duct of Wirsung and adjacent tissue in the head of the pancreas showed that the lumen of the duct was filled with bile-stained columnar cells and débris similar to that found in the common bile-duct. The walls of the duct were irregular and much thickened. Patches of columnar cells were found in the fibrous tissue of the walls and lying in the fibrous strands separating the neighbouring pancreatic lobules (Fig. 4). Preparations made from the head of the pancreas in various situations showed well-marked interstitial pancreatitis of the interlobular type, the lobules being separated by wide strands of fibrous tissue, which in places invaded the periphery of the lobules. Scattered in the interlobular tissue were small irregular patches of columnar cells, some of which occurred as solid masses, while others were grouped about a more or less distinct lumen. The latter, however, conld be readily distinguished from the normal interlobular ducts by the atypical arrangement of the cells and the absence of any iimiting membrane or duct wall. No direct invasion of the head of the pancreas by the growth appeared to have occurred and the patches of growth were most numerous in the neighbourhood of the duct of Wirsung (Figs. 5 and 6). Sections of the body and tail of the pancreas showed no marked overgrowth of interstitial tissue but the cells of the parenchyma were swollen and granular, having the histological characters seen in cloudy swelling.

The post-mortem examination thus proved that the cavity opened at operation was due to a columnar-celled carcinoma of the gall-bladder which had invaded the stomach and first part of the duodenum and was adherent to the colon. The obstruction of the pylorus caused by the growth accounted for the vomiting that occurred during life, and also explained the evidences of stagnation of the stomach contents found in the pathological examination. The destruction of the upper part of the common bile-duct, and the presence of a mass of disintegrated growth in its remaining section, were un. doubtedly the cause of the jaundice, but the bile-stained character of the cells in the lumen of the duct and the presence of stercobilin in the fæces showed that some bile was able to find its way along the duct into the intestine, the obstruction thus not being absolute as it is in most cases of primary cancer of the head of the pancreas.

The most interesting feature of the case is the condition of the pancreas and the duct of Wirsung. The latter was filled with débris similar to that found in the common bileduct, and as the part of the pancreatic duct nearest to this was stained with bile it was evident that not only had masses of cells passed from the common duct into the duct of Wirsung but that a certain amount of bile had also followed the same course. Accoraing to Opie the passage of bile into the pancreatic duct is a cause of acute pancreatitis, and although there were well-marked evidences of inflammatory changes these were not of the acute type, and during life there had been none of the symptoms usually associated with acute pancreatitis. Recent experiments by Flexner have tended to show that the active constituent of bile giving rise to inflammation of the pancreas is the bile salts, and that when these are modified by prolonged stay in the ducts or diluted with colloid material they cause chronic inflammation and not an acute fulminating lesion. This is probably, in part, the explanation of the pancreatitis found in the case under consideration. But in addition we have also to take into account the obstruction to the free outflow of the pancreatic secretion caused by the blocking of the ducts and the irritation of the gland by deposits of growth within its substance. The much more advanced stage of the lesion found in the head of the gland is possibly to be explained by its earlier invasion by the growth and its more direct contact with the bile passing from the common bileduct into the duct of Wirsung, but it has also to be borne in mind that malignant disease of the gall-bladder very frequently follows irritation by gall-stones and that chronic pancreatitis is also most commonly the result of the passage of biliary calculi along the common duct. The fact that there was advanced fibrosis of the head, while the body and tail only showed the characters of catarrhal pancreatitis, with no marked increase of fibrous tissue, lends support to the view that the affection of the head of the gland was of much earlier date than the disease of the body and tail of the organ.

The absence of any direct connexion, either macroscopically or microscopically, of the growth with the pancreas, the more numerous decosits of growth in the neighbourhood of the duct of Wirsung, and the absence of deposits elsewhere suggest that the involvement of the pancreas was by way of the common bile and pancreatic ducts. So far as we are aware this direct method of extension has not as yet been described and is a cause of pancreatitis of which we have no previous knowledge. It was no doubt rendered possible by the soft friable character of the growth, but as 
wancer of the bile-ducts may be of a similar nature the possibility of such an occurrence has to be borne in mind in making a diagnosis of pancreatitis.

The examination of the urine, frces, and stomach contents in this case suggested obstruction of the common duct with secondary chronic pancreatitis, and the histological examination afforded abundant evidence of the correctness of these conclusions, thus once again demonstrating the usefulness of these methods when carefully and correctly carried out. The inference as to the simple nature of the cause of the obstruction was, however, proved to be incorrect, but the condition was so anomalous and outside our previous experience that a correct conclusion was practically impossible.

An examination of the stomach contents for free and physiologically active hydrochloric acid has proved of assistance in two cases of malignant disease of the head of the . pancreas, but in this instance the results of this examination were misleading, as they had been in the cases of growth of the common duct previously mentioned. We are therefore of opinion that while the absence of free and physiologically active hydrochloric acid may afford aseful confirmatory evidence in suspected cases of cancer of the head of the pancreas, their presence, even in considerable amount, is not of any diagnostic value, especially when the growth is situated in the common duct or gall-bladder.

The case is clinically interesting as showing how closely cancer of the gall-bladder may simulate cholelithiasis, if the disease be associated with suppuration. The intermittency and severity of the attacks of pain for 13 months, without jaundice, suggested the presence of gall-stones in the cystic duct, and the last severe seizure, followed by jaundice, made it appear probable that a calculus had passed into the common duct. Although no gall-stones were actually found, either at the operation or later, it is quite possible that cholelithiasis may have been the original cause of the disease, and this is rendered probable by the presence of more advanced inflammatory changes in the head of the pancreas than could be accounted for by the recent invasion of the gland by malignant disease from the duct of Wirsung. The nodular character of the growth felt before operation and the reported lo:s of flesh and strength led to a suspicion of cancer, but the well-marked signs of suppuration gave the impression that some relief, and possibly something more than relief, might be given by the evacuation of the abscess.

On several occasions it has been the good fortune of one of us to operate under similar circumstances and to find the disease to be simple, the operation leading to complete and perfect recovery, but in this case it became at once apparent on opening the abdomen that merely temporary relief was all that could be hoped for.

Our experience in other cases of cancer of the pancreas has shown that an inflammatory condition is apt to supervene as a complication in a certain proportion of cases, and unless this is borne in mind it may lead to errors in diagnosis and to useless operation, for it must be acknowledged by all who have had experience of such cases that primary cancer of the pancreas is a hopeless disease however it may be sreated.

\section{CALCULI IN THE APPENDIX.'}

BY D. T. BARRY, M.D. R.U.I., F.R.C.S. ENG., D.P.H., DEMONSTRATOR OF PHYSIOLOGY IN QUEEN'S COLLEGE, CORK.

BEING at present engaged with Professor J. J. Charles in a little research work on the structure of the appendix my attention was directed to the subject of calculi and other bodies found in this organ by finding four small stones in one of the specimens submitted to me by Dr. D. P. Fitzgerald, our assiduous demonstrator of anatomy.

There seems to be no definite understanding as to the exact nature of these bodies, but that they are not always of the same kind is certain. Before attempting a classification I will give the results of a rough analysis of those specimens and a few extracts from recent literature on the subject. The appendix in this case was somewhat fusiform in shape, having a bulging middle and contracted ends. Microscopically the distal end for quite half an inch from the tip presented no lumen and no trace of glands or of lymphoid tissue. Between this and the distended site of the 1 A note read before the Cork Medical and Surgical Society on
March 20th, 1907 . calculi a portion intervened containing a plug of mucus in the lumen, a fairly regular set of glands, and showing some inflammatory changes. The distended portion showed atrophy of the mucous membrane and thinning of the muscular coat. The proximal end contained a plug of mucus. The calculi were four in number, each about two millimetres in diameter, dark brown in colour, smootb, and facetted. Allowed to fall on a plate they gave a ringing sound in no way differing from that given by a small gravel pebble of the same size. While engaged in this latter pastime I lost one of the precious stones.

The next step in the examination was to macerate one with a dilute solution of sulphuric acid and to test the surface layer microscopically and chemically for cholesterin. These tests were negative. Gmelin's test for bile pigments and Pettenkofer's test for bile salts also gave negative results. Further examination showed that the stones were composed chiefly of calcium phosphate with a small amount of organic matter.

To quote briefly from a few recent investigators:-

Howard Kelly " states : "Gall-stones, also, which formerly were supposed to enter the appendix frequently are exceedingly rare; but they are often so closely simulated by enteroliths that a chemical analysis is necessary for their exclusion. The clinical evidence in some of these cases so strongly supports the gall-stone theory as to leave no doubt in the mind of the observer." McAdam Eccles ${ }^{3}$ maintains that calculi in the appendix are always enteroliths and always formed in situ. Walsham and Spencer ${ }^{4}$ state : "The appendix may contain true fæcal concretions or coprolites. Enteroliths proper where the fæcal constituents and inspissated mucus are mixed with calcareous material derived from the inflamed wall, like tonsillar concretions and rhinoliths, are more rare, while foreign bodies, such as fruitstones, \&c., are still rarer." Roberts ${ }^{5}$ remarks: "They [gallstones] cause trouble by lodging in the vermifcrm appendix.' Lediard of the Cumberland Infirmary recently writing in THE LANCET describes a case on which be operated. The patient showed the usual signs of an acute appendicitis and there was no previous history of gall-stones or a symptom. pointing to them. In the appendix were found 11 small black stones, and they were found to consist of cholesterin and bile pigments. Murchison ${ }^{6}$ expresses strong doubt of the presence of gall-stones. Osler, ${ }^{7}$ in reference to gall-stones in the intestine, remarks : "Courvoisier's statistics give a total of 131 cases, in six of which the calculi had a peculiar situation as in a diverticulum or the appendix." He also states: "The lumen of the appendix may contain a mould of fæces. Concretions, enteroliths, coproliths are also common." 8

It is only by numerous analyses with careful reports of the separate cases met with that we can allay the uncertainty prevailing in connexion with this subject. It is important to arrive at some conclusion as to the different types of bodies found with the relative frequency of each. It will be seen from the above quotations that there is a confusion of terms. One concludes, for instance, that concretions, fæcal moulds, enteroliths, and coproliths are all distinct things, while in addition the terms stercolith and coprolite are used. Would it not be well to use the term fæcal mould for those masses of inspissated fæces somewhat resembling a date-stone in appearance and containing the usual percentage of inorganic matter found in fæeses? The term "enterolith" might well be employed for other forms where the inorganic material preponderates.

To my mind, a very important consideration in these cases is the condition of the appendix itself. If gall-stones migrate from main gut to appendix we should expect to find, according to the size and number of the stones, a patent lumen with more or less destruction of the mucous membrane over which the stone has passed. The case reported by Lediard, ${ }^{9}$ where 11 gall-stones seem to have thus migrated one after the other, must surely have presented some interesting features in structure to which no reference is made. The case here reported by me showed changes exactly corresponding to formation in situ and to formation as a result of increased inorganic matter accompanying inflammation.

In conclusion, I would express an opinion that, excluding

2 The Vermiform Appendix and its Diseases (Saunders)

3 THE LANCET, March 14th, 1903, p. 703.

Theory and Practice of Surgery, 1906.

clinical

The Principles and Practice of Medicine, p. 568.

8 Op. cit., p. 519

9 THE LAXCE', Jan. 12th, 1907, p. 83. 